UDC 373.2:159.922.7

Marianna AMIRAGHYAN

\title{
THE METHODICAL PRINCIPLES OF CHILD'S SPEECH DEVELOPMENT CURRICULUM
}

\begin{abstract}
In the article child's speech development process is observed, which, on the one hand, assumes the accounting of not only didactic, but also methodological principles, which let the preschool pedagogue choose appropriate means for speech development. On the other hand, the basis of the organization of speech development process is the preschool educational curriculum, where the volume of speech abilities and skills, the demands for different aged-groups are defined. But child's speech development peculiarities and regularities should be taken into consideration, when the choice of self-realization and self-organization methods, ways and means of child's speech becomes urgent.
\end{abstract}

Keywords: speech development, speech abilities and skills, preschool speech development curriculum.

The human society is continually developing, social life, being in movement, is always submitted changes and, as a result of this, new problems and demands are aroused - full of contrasts. The solutions of these problems bring development in social life. It's known, that human being intends not to adapt to new conditions, but to perceive suggested problems and find solutions for them.

Our society has social-communicative progress. All the sciences are developing, too. The society - education, science - education - society relationships are improving. And a discrepancy, among these spheres' demands, is aroused. An abrupt and rapid growth of necessary knowledge for a human occurs. It becomes important to orient quickly, communicate rightly, organize own actions properly in the created situation. The mechanically perception of the amounts of dates becomes unnecessary any more: the consciously and comprehensibly acquisition of knowledge becomes a must, which means to find solutions via new ways and methods.

All the changes mentioned above, have their direct influences on educational system. Proceeded from nowadays' problems, the demands for younger generation's breeding, teaching and educational processes are being changed. It becomes important to improve educational contents, teaching ways and methods. Pedagogue - psychologists have to seek and systematize new teaching methods, by using which it will be possible to develop children's cognitive activity, creative process and be able to follow sciences' developing motion. A necessity of educating, forming and developing new generation as self- think- 
ing people, who will be able to enrich knowledge, express their thoughts literately and speak coherently, logically and meaningfully, becomes a must.

From this, two urgent objectives are aroused:

1. to seek new effective developing ways and means for children's breeding process,

2. to review preschooler's speech development methodology making it as a means of solving recurrently problems, which occur during the communication.

These two urgent and mutually connected objectives should have their reflections in the modern educational curriculums, which are the cornerstone of realizing education.

It is known that each human activity is realized successfully, if it has a properly organized curriculum, where every step is carefully worked out, if the means, ways of carrying out of a certain activity are represented ("Preschool Curriculum Framework," 2010, p. 30). In order to realize preschooler's speech developmental process, it is necessary to have a systematized, compact curriculum, which will promote the organization of child's speech development process. Of course, we mean the speech development section of the curriculum for senior preschoolers aged of $5-6$.

There are some educational complex curriculums in our preschool establishments: 'Preschool educational breeding complex curriculum', 'Kindergarten' preschool educational curriculum', 'Educational complex curriculum for senior group in kindergarten'. The demands for child's speech development are reflected in these curriculums, where each objective of speech development is rep- resented. Of course, these curriculums somehow lead preschool teachers to organize senior preschoolers' speech development process, but we find that these curriculums need to be reviewed and recompleted, because the peculiarities of forming preschooler's speech abilities and language capacities haven't been taken into consideration. Especially the following factors aren't systematized in the curriculum:

- the linguistic-psychological points of departure of child's speech development, which can be bent by nowadays' demands,

- the main principals of organizing speech development process, rules, proceeded from them, nowadays' demands,

- senior preschooler's speech manifestations - criteria, the analyze of which can promote the perfection of speech development methodology,

- the methodical peculiarities for the lessons of speech development.

From the lack of the factors, mentioned above, the organization of child's speech development process suffers.

There are a lot of theories for child's speech development suggested by pedagogues (Yan Am. Komensky, who connected the peculiarities of child's development with the speech process, Ye. Tikheyeva, who connected speech development with child's activity and social environment), psychologisys (A. Leontev, L. Vigotsky, who emphasized social nature of speech), linguists (Noam Chomsky, who gave emphasized the role of transformational grammar, due to which children can make a lot of sentences (Peter, 1986, pp. 282-284), pedagogue-methodists (F. Sokhin, who mentioned that senior pre- 
schoolers are able to conscious language units), Armenian pedagogues Kh. Abovyan, Gh. Aghayan, A. Bahatryan, G. Edilyan, who attached importance to the organization of child's speech development process.

Accepting the approaches above, we consider, that during the organization of child's speech development process we should emphasize the combination of inner and outer sides of speech. We find that, in order to achieve success in child's speech development process, we should take into consideration this factor, and the methodology of speech development must derive from this point of view, when the analyze of child's speech manifestations will allow to reveal the inner organization of child's speech and find appropriate methods, means and ways to increase the efficiency of speech development process. Children at preschool age, particularly senior preschoolers /5-6 - year - old/, can control their outer speech through inner speech. And we suppose, that at senior preschool age developed speech standard is inwardly controlled speech. Senior preschooler is able not only to control his/her lexicon, coherent speech but also grammatical and phonetic structures of the speech. But this occurs only during communication with peers, especially when children try to explain the rules of a game to their players. As a result, senior preschooler master and estimate own speech, control language material internally and becomes a master and possessor of language system.

Methodological basis of speech development is the material-philosophical approach, according which language is a result of social-historical development, in its nation's culture, traditions, social relationships are reflected (Alekseeva \& Yashina, 2000, pp. 7-10). Language is an important means of communication and social mutual activity among people, and is connected with thinking. This philosophical approach reveals the meaning of the perception of language as a difficult human activity, during which knowledge is acquired, abilities are formed. Language, speech are aroused during human activity, and language, as a result of the activity, reflects contents, conditions and results of the activity. From this, an important principal of methodology arouses: perception of language units, formation of speech abilities and communicational skills among children occur during the activity, and the motive is the demand for communication. During communication child perceives speech actively. Though language and speech are united, they are not the same. There is a great difference between language and speech. Language has been aroused during social-historical development, about which we have already mentioned above. Language is the form of the expression of peoples' consciousness, whereas speech is the form of the expression of a person's consciousness. Speech belongs to a person. Language is a means of communication, speech is the process of communication. Speech is the usage of language. In our speech we use the units of language, make expressions, sentences, texts, we express our thoughts with the help of language units in our speech.

The next methodical nature of language is reflected in its connection with thinking. Language is the implement of thinking and cognition. From this, during speech teaching the methods will be productive, if they pro- 
mote both speech and thinking development (Clark, 1984, pp. 28-32).

From this, five major properties of all human languages are distinguished. The first property is that language use is creative. Language is merely a complicated habit, a set of acts by ear and mouth that have been acquired by memorization and practice. On this view, the explanation of talking is simple: each of the memorized speech acts is simply performed whenever the appropriate circumstances arise. The next property of language is that language is highly structured, which means that sentences are made in lawful, not accidental way. We construct our sentences in accordance with certain general principles which are often called rules of grammar. The third property is that language is meaningful. Each word in a language expresses a meaningful idea, about something, action, abstraction, relation, quality and so on. The purpose of language is to express all these meanings. The next property is that language is referential, that is, it refers to and describes things and events in the real world. Language users know more than how to put words together into sentences. They also know which words refer to which things, events and scenes in the world. The problem of reference is a complicated one: we refer not to what we see in the world. Rather, we refer to whatever it is in the world that we think about. The fifth property of language is that it is interpersonal, involving the thoughts of more than one person at a time. The primary uses of language are in functions that cross from one individual to another. To accomplish these social ends, speakers must know not only a language, but rules for using language appro- priately in successful communication (Gleitman, 1983, pp. 226-232).

Language is organized as a hierarchy of structure. At the bottom of the hierarch, language consists of little snippets of sound, and at the other end, of sentences and conversations. From this, we'd like to introduce the components of language:

- phonology involves the rules about the structure and sequence of speech sounds,

- semantics consists of vocabulary and how concepts are expressed through words,

- grammar involves two parts. The first, syntax, is the rules in which words are arranged into sentences. The second, morphology, is the use of grammatical markers (indicating tense, active or passive voice etc.),

- pragmatics involves the rules for appropriate and effective communication.

The latter side of language involves other three sides, and we are sure that especially this side should be formed at preschool age.

The philosophical perception of language methodology, mentioned above, should be the basis of speech development curriculum. This approach allows us to define the following principles for the organization of speech development process:

- the principle of mutual connection among sensuous, mental and speech development of children. This principle is closely connected with the acknowledgement of surrounding. The perception of language material occurs through deciding mental tasks. This means that preschool pedagogue should use visual aids, means and methods of teaching directed to child's cognitive development. 
- The principle of communication-activity approach to the speech development, according to which, speech is observed as an activity, where language is used for the aim of communication. This principle allows kindergarten teacher to use such materials which will promote the formation of children's communicative abilities. This principle changes teaching methods, where the formation of child's speech manifestations becomes initial.

- The principle of language sensitivity, when the child perceives the rules of language unconsciously. Preschoolers are able to combine language units correctly, though they don't realize these rules. Pedagogues should seek for such methods, which will let develop children's language sensitivity. This can be developed through word games.

- The principle of forming child's elementary understanding of language phenomena. The basis of this principle is that children not only imitate adults' speech, but they unconsciously generalize language phenomenon as well. It forms an inner system of language rules, which allow the child to create new expressions. During the teaching process kindergarten teacher should use methods directed to the development of child's awareness of language phenomena (F.A. Sokhin). Language awareness is an indicator of the degree of the formation of speech skills.

- The principle of complete approach toward teaching of different sides of speech. It's known that speech development process solves different objectives of speech: mastering vocabulary, pronunciation skills, grammatical structure, development of dialogue and monologue speech. These parts of speech are isolated for didactic purpose, but they are interrelated parts of a whole - the process of mastering language system: during the development of one side, others develop too. But the aim of kindergarten teacher should be the formation and development of children's coherent speech manifestations, where all the parts of speech are expressed.

- The principle of enrichment of motivations of speech activity. Enrichment of motives of children's speech activity during learning process is very important, because positive motivation of speech increases the effectiveness of teaching. During speech development lessons pedagogue offers children to answer questions, retell stories, repeat something, but it is not taken into consideration, whether the child need to do so. Hence, an important task for pedagogue is the creation of positive motivation for every action of the child in the learning process, as well as the organization of situations that cause the need for communication. The usage of a variety of interesting techniques for the child is very important, which will stimulate their verbal activity and contribute to the development of speech creative abilities

- The principle of active speech practice. The essence of this principle is that language is learned through its usage, in practice. Reuse of language units in changing environments allows to develop a strong and flexible language skills. Speech activity is not only speaking, it is also listening, the perception of speech. Therefore, it is important to teach children to 
perceive and understand others' speech. Thus, during lessons it is important to use variety of factors providing speech activity for all children, positive emotional background, communication among children. The usage of this principle provides wide practice of language use for all the children, not only during the lessons, but during other activities as well (Alekseeva \&Yashina, 2000, pp. 48-50)

So, language acquisition by children occurs during communication, which allows to perceive language structure and use it in the speech. This means that we can't teach children language via traditional lessons, which are sometimes dull for preschoolers. And the principles, mentioned above, provide communicative environment for children in kindergartens. The realization of this principles make kindergarten teachers use interactive methods and ways during language teaching. Hence, the preschool educational curriculums, which are used in our preschool establishments should be worked out according to these principles mentioned above. The analyses of those curriculums has proved, that, though they express some demands for senior preschooler's speech development, they are not systematized and defined, moreover, they don't help kindergarten teachers in the choice of methods, ways and means. All these principles derives from the peculiarities of children's speech development. This means, that during speech development process all the chosen methods and ways should be bent through the characteristics of child's development. These principles allow kindergarten teachers to organize speech development process from the children's speech specifities. Children's speech developmental peculiarities dictate adults to choose appropriate methods and ways for organizing their speech development process. It's without saying that children with well-developed oral language are likely to succeed in reading and writing comprehension in later grade levels than children with less well-developed oral language.

\section{REFERENCES}

Alekseeva, M.M., \& Yashina B.I. (2000). Metodika razvitiya rechi i obucheniya radnomu yazyku doshkol'nikov (Preschooler's Methodology of Speech Development and Teaching Mother Tongue, in Russian). Moscow: Akademiya.

Clark, P.V., \& Eschholz, A. P. (1984), Language. New York.

Gleitman, H. (1983). Basic Psychology. New York.

Preschool Curriculum Framework (2010). California: Sacramento.

Reich, P.A. (1986) Language Development. New Jersey: Prentice-Hall. 